\title{
Ações afirmativas: análise comparativa de desempenho entre cotistas e não cotistas em uma universidade pública
}

\section{Affirmative actions: comparative performance analysis between quota and non- quota in a public university Acciones afirmativas: análisis comparativo del desempeño entre con y sin cuota en una universidad pública}

\author{
ANDRÉ FERREIRA \\ Orcid Id: http://orcid.org/0000-0002-1430-4537 \\ Universidade Federal Fluminense \\ RAQUEL DE SOUZA CORRÊA \\ Orcid Id: https://orcid.org/0000-0002-2483-2405 \\ Universidade Federal Fluminense \\ THAMIRES DOMINGOS PAREDES GALANTINI \\ Orcid Id: https://orcid.org/0000-0002-4192-8134 \\ Universidade Federal Fluminense \\ MÁRCIO MOUTINHO ABDALLA \\ Orcid Id: http://orcid.org/0000-0002-2607-1021 \\ Universidade Federal Fluminense
}

\begin{abstract}
Resumo: Este trabalho teve como objetivo verificar o desempenho acadêmico de cotistas em relação aos não cotistas. A pesquisa foi realizada, por meio de estudo de campo, com 265 egressos do curso de Administração da Universidade Federal Fluminense (UFF). Foi realizada uma análise dos coeficientes de rendimento acadêmico dos alunos que ingressaram através de cotas, bem como daqueles que ingressaram por ampla concorrência. O principal resultado indica que a política de ação afirmativa de cotas não impactou negativamente na formação do egresso do curso avaliado.
\end{abstract}

Palavras-chave: Avaliação de Políticas Públicas; Ações Afirmativas; Cota na Universidade Pública; Inclusão Social

\begin{abstract}
This paper aimed to verify the academic performance of quota students in relation to non-quota. The research was carried out, by means of a field study, with 265 egresses of the Administration course at the Universidade Federal Fluminense (UFF). An analysis was made of the academic performance coefficients of students who entered through quotas, as well as those who entered through wide competition. The main result indicates that the policy of affirmative action of quotas did not have a negative impact on the formation of the graduates of the evaluated course.
\end{abstract}

Keywords: Public Policy Evaluation; Affirmative Actions; Quota at the Public University; Social Inclusion. 
Resumen: Este trabajo tuvo como objetivo verificar el rendimiento académico de los egresiones con cuota en relación con los egresiones sin cuota. La investigación se realizó, mediante un estudio de campo, con 265 egresiones del curso de Administración en la Universidad Federal Fluminense (UFF). Se realizó un análisis de los coeficientes de rendimiento académico de los estudiantes que ingresaron a través de cuotas, asi como de aquellos que ingresaron a través de una competencia amplia. El resultado principal indica que la politica de acción afirmativa de las cuotas no tuvo un impacto negativo en la formación de los graduados del curso evaluado.

Palabras clave: Evaluación de politicas públicas; Acciones afirmativas; Cuota en la Universidad Pública; Inclusión social.

\section{INTRODUÇÃO}

Por muitos anos, o acesso à universidade pública esteve quase que em sua maioria destinado à uma fração privilegiada da sociedade: alunos oriundos de escolas particulares, brancos e favorecidos economicamente formavam o perfil predominante dos ingressantes no ensino superior público (BEZERRA; GURGEL, 2012).

A inexpressiva representatividade da população negra e parda e de baixa renda nas instituições públicas de ensino superior deveu-se, em grande parte, à discriminação racial e social sofrida no passado. Desse modo, evidencia-se o fato de que, infelizmente, o acesso ao sistema nacional de educação superior ainda é restritivo e pouco acessível às diversas camadas populacionais no Brasil (OLIVEIRA et al., 2008).

O histórico de implantação de políticas públicas de cotas no Brasil ainda é recente. Iniciou-se na Universidade do Estado do Rio de Janeiro (UERJ) nos anos 2000 e, posteriormente, outras universidades foram adotando essa forma de ingresso. Porém, somente no ano de 2012 tornou-se lei federal a reserva de vagas de universidade pública considerando critérios raciais e sociais. Em comparação, na Índia a política de cotas começou a ser adotada no ano de 1950 (FERES JR; DAFLON, 2015).

Com a aprovação da Lei 12.711/2012 ou Lei de Cotas, o perfil dos ingressantes em universidades públicas tem retratado um novo cenário na educação. As políticas públicas de ações afirmativas, comumente denominadas de cotas, têm sido o modo adotado para ampliar a inclusão social e democratização do ensino superior público brasileiro (OLIVEIRA et al., 2008, QUEIROZ et al., 2015). 
A política pública de ações afirmativas é um modo de inclusão social, isto é, visa minimizar os danos causados pela discriminação social e, principalmente, racial sofrida ao longo da história. Por séculos uma parcela da sociedade, formada por negros, pardos e indígenas, foi vítima de injustiças e violação de direitos humanos (PIOVESAN, 2005; OLIVEN, 2007).

Neste contexto, esta pesquisa busca verificar, por meio de um de estudo de campo, se a Lei de Cotas, ao democratizar o ingresso no ensino superior, produziu algum impacto no desempenho acadêmico dos egressos. Para isto foram mensuradas as médias obtidas pelos alunos do curso de Administração da Universidade Federal Fluminense - Volta Redonda, no decorrer de sua formação na graduação e analisadas as discrepâncias no desempenho acadêmico de discentes que ingressaram por meio de ações afirmativas, em relação aos discentes ingressantes na modalidade de ampla concorrência.

A pesquisa está estruturada em quatro partes. Na seção seguinte tem-se o referencial teórico, que aborda sobre (i) Ações Alternativas e Política Pública de Inclusão na Área de Educação, (ii) Análise Crítica da Lei de Inclusão e (iii) Estudos sobre desempenho acadêmico de cotistas. A segunda seção apresenta as decisões e o percurso metodológico, desenvolvido com o intuito de responder à questão que norteia a investigação. Na terceira seção é realizada a análise e discussão dos resultados, e por fim, são apresentadas as considerações finais da pesquisa.

\section{POLÍTICA PÚBLICA DE INCLUSÃO NA ÁREA DE EDUCAÇÃO}

A educação não somente reduz a taxa de desemprego, mas propicia o aumento da remuneração do indivíduo. No mercado de trabalho nacional, trabalhadores que concluem a graduação possuem uma taxa menor de desemprego e um retorno financeiro maior, cerca de 2,6 vezes, se comparado com os indivíduos que cursaram somente até o ensino médio (CARVALHO, 2011). A sociedade também se beneficia com os resultados que a educação superior acarreta, com destaque para melhor qualificação da mão de obra disponível (BEZERRA; GURGEL, 2012; WALTENBERG; CARVALHO, 2013).

Contudo, o acesso à educação até recentemente não era uma realidade para as classes menos favorecidas. Seja para o ingresso ao ensino superior, seja para inserção no mercado de trabalho, muitos cidadãos já sofreram com a falta de oportunidade por pertencerem a determinada classe social ou étnica (OLIVEIRA et al., 2008). 
Assim, existe uma lacuna educacional entre estudantes brancos, negros e pardos, caracterizada muito mais pela sub-representação histórica das populações negra nas universidades do que pela diferença entre o conhecimento de alunos cotistas e não-cotistas (DURHAM, 2005).

A segregação e exclusão social sofrida por negros, pardos e indígenas e os menos favorecidos economicamente tornou-se um problema público e, por isso, passou a ocupar um lugar na agenda (IIZUKA, 2016).

Estas políticas de inclusão ainda sofrem resistência por parte de determinados grupos da sociedade. Um exemplo foi a realização de passeatas na cidade Aracajú no ano de 2006 contra o sistema de cotas implantado pela Universidade Federal do Sergipe. Tal manifestação pode estar associada à questão do mérito, entretanto, as cotas não acabam com a meritocracia, pois os grupos continuam a concorrer por vagas, embora sob um novo contexto (MOURA; TAMBORIL, 2018).

Dada esta contextualização, surge a necessidade de o Estado agir e desempenhar uma de suas funções, a de criador de políticas públicas. Para Souza (2006), a formulação de Políticas Públicas consiste na real implementação de propostas realizadas pelos governos em períodos eleitorais. Em outras palavras, traduz-se em colocar em prática aquilo que foi planejado e prometido, propiciando resultados e mudanças reais na (e para a) sociedade.

Política pública de ação afirmativa diz respeito à busca por reparação aos danos que determinados grupos sofreram no passado, impedindo que estes tivessem oportunidades de ingressarem no mercado de trabalho, no ensino superior e em cargos de representação política. Desse modo, a ação afirmativa visa minimizar e, se possível, acabar com os desequilíbrios nestes cenários. Sendo, portanto, um mecanismo para equidade de oportunidades e ascensão das minorias (OLIVEN, 2007).

Em outras palavras, a política pública de ação afirmativa é entendida como uma medida redistributiva, isto é, capaz de alcançar um maior número de indivíduos ao gerar perdas efetivas a dado grupo em um curto período de tempo, e em contrapartida gera ganhos indefinidos e futuros a outro grupo de pessoas. Em vista disso, a política redistributiva objetiva reservar recursos para grupos socialmente excluídos (SOUZA, 2006; CAMPOS et al., 2017).

Veloso (2009) se posiciona contrário às ações afirmativas de cotas, pois em sua concepção, o déficit na formação dos alunos oriundos de escolas públicas é visto como um risco à qualidade do ensino superior, sendo este, o principal fundamento das críticas em relação à política de cotas. 
As ações afirmativas têm aplicações bastante distintas mundialmente. Oriunda da Índia em 1950, as ações afirmativas de reserva de vagas nas legislaturas, no serviço público e no ensino superior começaram a ser implantadas logo após a independência do país visando os grupos excluídos na sociedade. Posteriormente, os Estados Unidos, em 1960, também começaram a adotar as ações afirmativas objetivando melhores condições de vida e igualdade de oportunidades para a população negra, sendo o marco desta mudança a extinção das leis segregacionistas. Com o decorrer dos anos, essas políticas foram se estendendo à Europa e à países como a Austrália, o Canadá, a África do Sul e a Argentina e passou a representar a luta pelos direitos das minorias de modo geral (MOEHLECKE, 2002; FERES JR; DAFLON, 2015).

Apesar de a história apresentar esforços, com os mais diversos propósitos, de estabelecer cotas educacionais, a exemplo da chamada Lei do Boi de 1968 e da Lei dos dois terços, no Brasil, o histórico de implantação de políticas públicas de ações afirmativas de cunho social é recente. Tendo início, em 2003, na Universidade do Estado do Rio de Janeiro (UERJ), em decorrência da Lei Estadual nº. 4.151, que consiste na reserva de vagas das universidades estaduais para alunos negros e oriundos de escola pública. A posteriori, foi crescendo a demanda e a pressão popular pela expansão desta política pública também às universidades federais (FERES JR; DAFLON, 2015).

Em busca de mudanças no modo de ingresso ao ensino superior brasileiro, essas políticas públicas de inclusão social foram sendo criadas e implementadas (MOEHLECKE, 2002), iniciando-se, efetivamente, a partir da Lei 12.711/2012 que será abordada na próxima seção.

\section{LEI DAS COTAS}

Embora os problemas públicos como a discriminação racial e a desigualdade sempre estiveram presentes em nossa sociedade, por um longo período estes não ocuparam um lugar na agenda de discussão de políticas públicas do país. Contudo, essa conjuntura começou a se modificar no início dos anos 2000, mais especificamente, a partir do governo do Partido dos Trabalhadores (FERES JR; DAFLON; CAMPOS, 2012).

No governo de Fernando Henrique Cardoso (FHC) se iniciaram as discussões e o reconhecimento da discriminação racial. Um marco desta luta foi a participação do Brasil na Conferência Mundial Contra o Racismo que ocorreu no ano de 2001 em Durban, África do Sul. Nesta conferência foi assinada a 
Declaração de Durban, na qual o país se comprometeu em formular políticas públicas de ações afirmativas com o intuito de combater a discriminação racial (LIMA, 2010; SANTOS, 2012).

Dessa maneira, ao realizar uma linha do tempo sobre a história das ações afirmativas no Brasil percebe-se que (i) a implementação desta política pública se deu tardiamente ao considerar outros países, (ii) a primeira iniciativa, efetivamente, se deu com a Lei Estadual n ${ }^{\circ} 4.151$ em 2003, (iii) concomitantemente, no ano de 2003, iniciava-se o governo do presidente Lula, marcado pela ampliação e criação de programas de inclusão no ensino superior, como o Fundo de Financiamento ao Estudante do Ensino Superior (Fies), o Programa Universidade para Todos (ProUni) e o Programa de Apoio a Planos de Reestruturação e Expansão das Universidades Federais (REUNI), por fim, (iv) com a presidente Dilma, a Lei ${ }^{\circ}$ 12.711/2012 foi implementada, sendo esta responsável por modificar o cenário do ensino superior público ao tornar obrigatória a reserva de $50 \%$ das vagas considerando critérios raciais e sociais (LIMA, 2010; FERES JR; DAFLON; CAMPOS, 2012).

A Lei das Cotas foi implementada visando, basicamente, dois objetivos. O primeiro deles, criar uma padronização das políticas públicas de inclusão, uma vez que, a falta de legislação fez com que cada universidade adotasse uma regra diferente para o ingresso com cotas. E o segundo, ampliar a abrangência e tornar obrigatória a reserva de vagas no ensino superior para os negros, os pardos e os indígenas e menos favorecidos economicamente.

A Lei $n^{\circ} 12.711 / 2012$ que estabelece os parâmetros para o ingresso nas universidades federais e nas instituições federais de ensino técnico, define que, no mínimo, $50 \%$ das vagas para ingressantes nos cursos de graduação do ensino público superior serão destinadas a alunos que cursaram integralmente o ensino médio em escolas públicas. De acordo com o parágrafo único, $50 \%$ destas serão reservadas para estudantes cuja a renda familiar seja igual ou inferior a 1,5 saláriomínimo (BRASIL, 2012).

$\mathrm{Na}$ sequência do texto da lei, o Art. $3^{\circ}$ determina que as referidas vagas do Art. $1^{\circ}$ serão destinadas a indivíduos autodeclarados pretos, pardos e indígenas, e com deficiência (BRASIL, 2012). Desse modo, apenas nos artigos $1^{\circ}$ e $3^{\circ}$ a legislação já englobam parcelas da população que são excluídas devido à critérios socioeconômicos e raciais, conforme ilustra a Figura 1. 


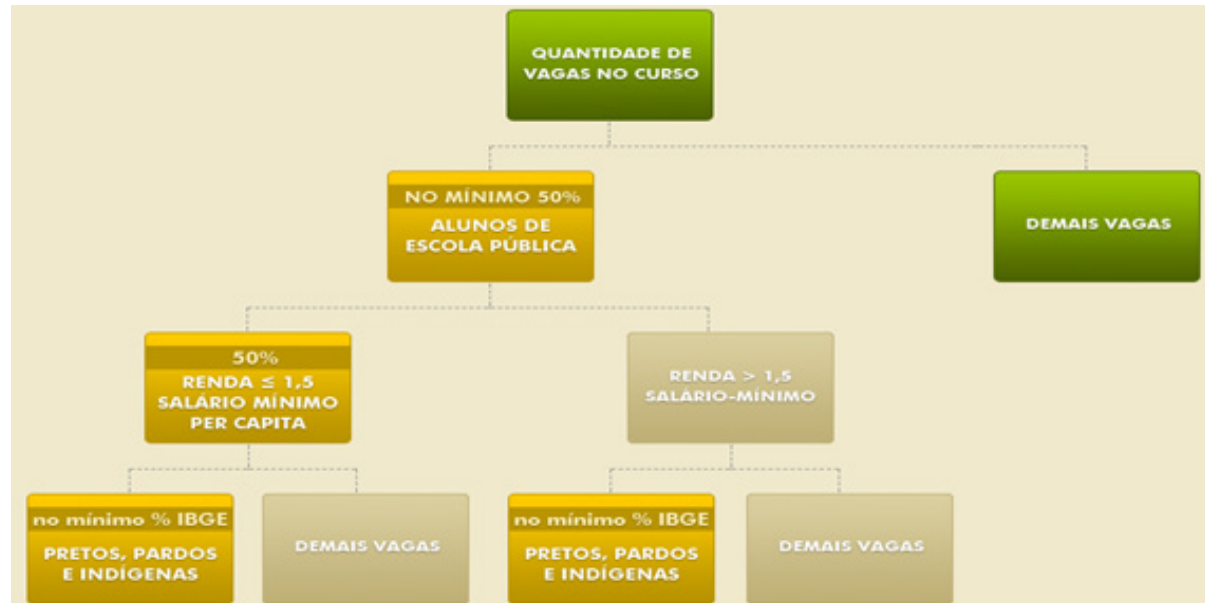

Fonte: BRASIL (2012).

De acordo com o texto da legislação, as instituições contempladas pela Lei de Cotas teriam o ano de 2016 como o prazo limite para implantar esse novo sistema de ingresso (BRASIL, 2012).

É evidente a importância da Lei de Cotas para o avanço da democratização do ensino superior público. Apesar de ser um mecanismo capaz de mitigar as desigualdades para ingresso no ensino superior, a legislação abordada não é suficiente para tratar de todas as deficiências no cenário educacional. Desse modo, torna-se necessária a implementação de outras medidas que visem esta democratização, como a melhoria do ensino básico e na distribuição de renda e a luta contra a discriminação, possibilitando a real inclusão destes indivíduos na sociedade (SANTOS, 2012). Dentre estas medidas necessárias podem se destacar a ampliação de políticas de retenção, como bolsas para alunos em situação vulnerável, apoio para alimentação e transporte, ampliação de alojamento estudantil, dentre outras.

Um dos métodos para se verificar a eficácia da Lei de Cotas é a análise do desempenho acadêmico dos alunos cotistas que será abordado na próxima seção.

\section{INDICADOR DE DESEMPENHO ACADÊMICO - UFF}

Cada universidade possui um regulamento dos cursos de graduação (RCG), no qual são determinadas as diretrizes de funcionamento da instituição. Dentre os tópicos contemplados no RCG da Universidade Federal Fluminense (UFF), o Título VI - Das Avaliações, Capítulo I - Das Avaliações Regulares, 
o Art. 109 trata do aproveitamento escolar do aluno que "será expresso pelo Coeficiente de Rendimento e registrado no Histórico Escolar" (UFF, 2015).

O cálculo do coeficiente de rendimento (CR) será feito com base nas notas obtidas pelo discente nas disciplinas cursadas desde o ingresso no curso (UFF, 2015).

De acordo com o Art. 109 - RCG001/2015, o cálculo do CR será obtido por meio da fórmula a seguir, conforme figura 2 :

Figura 2 - Cálculo coeficiente de rendimento

\section{$C R=\underline{(C h 1 \times N ~ 1)+(\operatorname{Ch} 2 \times N 2)+\ldots \ldots(C h n \times N ~ n)}$, $\mathrm{Ch} 1+\mathrm{Ch} 2+\ldots .+\mathrm{Ch} \mathrm{n}$}

Fonte: Regulamento dos Cursos de Graduação - UFF (2015).

Onde:

- Ch n: Carga horária da disciplina n

- $\mathrm{N}$ n: Nota obtida na disciplina $\mathrm{n}$

Os alunos ingressantes na modalidade de ampla concorrência e de ações afirmativas estão sujeitos ao mesmo indicador para verificação do desempenho acadêmico (UFF, 2015). Em vista disso, nesta pesquisa foi utilizado o CR para comparar o rendimento acadêmico entre os alunos cotistas e não cotistas do curso de Administração do ICHS/UFF.

\section{DECISÕES METODOLÓGICAS}

A presente pesquisa é classificada quanto à sua natureza como pesquisa aplicada, visto que, pretende gerar conhecimento para aplicação prática, isto é, direcionada à solução de problemas em contextos específicos (GIL, 2002). É classificada quanto aos seus objetivos como descritiva, pois apresenta as características de certa população e fenômeno. Podendo assim, indicar correlações entre determinadas variáveis, sem a necessidade de esclarecer os fenômenos descritos (MARCONI; LAKATOS, 2004).

Quanto aos procedimentos técnicos, trata-se de um estudo de campo, que visa o aprofundamento das questões propostas, em que o planejamento do estudo de campo apresenta maior flexibilidade do que o levantamento e investiga profundamente poucos objetos de modo a obter um conhecimento detalhado (GIL, 2002). Nesta pesquisa tem-se como objeto de estudo o desempenho acadêmico de egressos do curso de Administração, da Universidade Federal 
Fluminense, campus Volta Redonda. Os dados necessários foram solicitados à UFF e obtidos por meio do sistema acadêmico da universidade, o IdUFF. Sendo, portanto, classificados como dados primários, pois estes ainda não foram submetidos às análises. Por fim, quanto à abordagem a pesquisa é classificada como quantitativa, isto é, utiliza-se da quantificação na coleta e no tratamento dos dados por meio de métodos estatísticos (RICHARDSON; PERES, 1999).

Buscando atingir o objetivo proposto pela pesquisa, definiu-se o período de 2014-2016 para a coleta de dados. Obtendo uma amostra de coeficiente de rendimento de 265 egressos. Esta decisão justifica-se por ser um período no qual a Lei 12.711/2012 já havia sido implementada e por marcar a integral adesão ao Sistema de Seleção Unificada (Sisu) como forma de ingresso na UFF, o qual faz uso da nota obtida no Exame Nacional do Ensino Médio (Enem).

Os coeficientes de rendimento dos egressos foram coletados e divididos entre aqueles que ingressaram por meio de ações afirmativas e de ampla concorrência. Após esta seleção, os dados foram analisados e comparados entre si.

\section{ANÁLISE E DISCUSSÃO DOS RESULTADOS}

O período selecionado para coleta de dados desta pesquisa possui dois momentos significativos, um que antecede e outro que sucede à efetiva implementação da Lei 12.711/2012 nas universidades públicas, conforme Figura 3.

Figura 3 - Número proporcional de ingressantes UFF 2014-2016

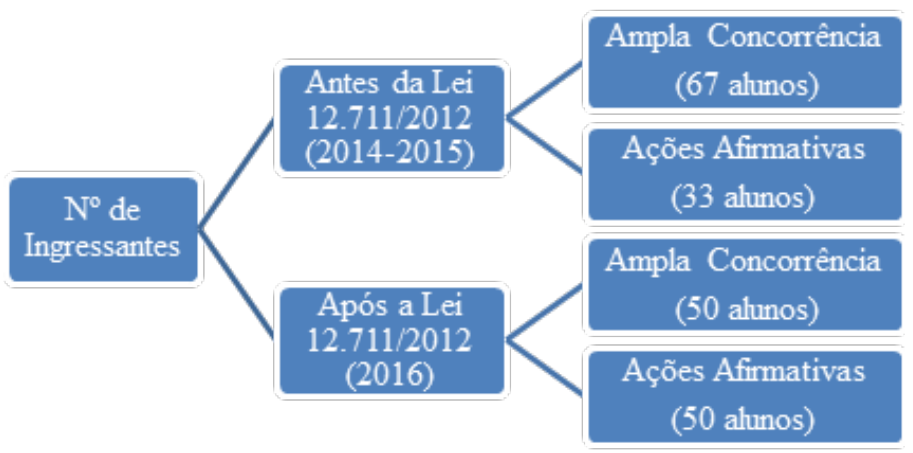

Fontes: Dados da pesquisa. 
A partir destes dados, depreende-se que antes da implementação da Lei $12.711 / 2012$ cerca de $67,3 \%$ das vagas foram preenchidas por candidatos de ampla concorrência, sendo reservadas $32,7 \%$ das vagas aos ingressantes por meio de ações afirmativas. Após a implementação da Lei de Cotas, essa diferença se anula, tornando-se equilibrada a distribuição de vagas entre alunos cotistas e não cotistas.

Para melhor compreensão, as modalidades de ingresso são apresentadas na Quadro 1, apresentada a seguir.

\section{Quadro 1 - Modalidades de ingresso UFF}

\begin{tabular}{|c|c|}
\hline $\begin{array}{l}\text { Modalidades de } \\
\text { Ingresso }\end{array}$ & Definição \\
\hline Ampla Concorrência & $\begin{array}{l}\text { Direcionadas a todos os alunos que tenham realizado o Enem. Não há pré- } \\
\text { requisito para candidatar-se. }\end{array}$ \\
\hline L1 & $\begin{array}{l}\text { Candidatos com renda familiar bruta per capita igual ou inferior a } 1,5 \text { salário } \\
\text { mínimo que tenham cursado integralmente o ensino médio em escolas públicas } \\
\text { (Lei } n=12,711 / 12) \text {. }\end{array}$ \\
\hline 12 & $\begin{array}{l}\text { Candidatos autodeclarados pretos, pardos ou indigenas, com renda familiar bruta } \\
\text { per capita igual ou inferior a } 1,5 \text { salário mínimo e que tenham cursado } \\
\text { integralmente o ensino médio em escolas públicas (Lei } n=12,711 / 2012 \text { ). }\end{array}$ \\
\hline L3 & $\begin{array}{l}\text { Candidatos que, independentemente da renda (art, } 14, \mathrm{II} \text {, Portaria Normativa } \mathrm{n} \text {. } \\
\text { 18/2012), tenham cursado integralmente o ensino médio em escolas públicas (Lei } \\
\mathrm{n} \approx 12711 / 2012 \text { ). }\end{array}$ \\
\hline 14 & $\begin{array}{l}\text { Candidatos autodeclarados pretos, pardos ou indigenas que, independentemente } \\
\text { da renda (art, 14, II, Portaria Normativa no 18/2012), tenham cursado } \\
\text { integralmente o ensino médio em escolas públicas (Lei no 12,711/2012). }\end{array}$ \\
\hline A1 & $\begin{array}{l}\text { Candidatos que cursaram todo o ensino médio em estabelecimento da rede } \\
\text { pública estadual ou municipal de qualquer unidade da federação, excluídos os } \\
\text { colégios federais, universitários, militares e de aplicação. Política de Ação } \\
\text { Afirmativa da UFF. * }\end{array}$ \\
\hline
\end{tabular}

$\left({ }^{*}\right)$ Essa modalidade foi extinta no ano de 2015.

Fonte: UFF (2018)

Conforme pode ser verificado, a Lei 12.711/2012 compreende quatro modalidades de ingresso ao ensino superior público. Ao demonstrar que a lei se tornou uma importante política pública de inclusão social, buscou-se analisar e comparar o desempenho acadêmico entre os ingressantes por ampla concorrência e por ações afirmativas.

A primeira análise compreendeu, simultaneamente, os 265 alunos ingressantes no período de 2014-2016. Estes foram separados entre cotistas e não cotistas e, posteriormente, foi calculada a média que representa cada uma das modalidades de ingresso. As médias obtidas a partir dos coeficientes de 
rendimento dos ingressantes por ampla concorrência e por ações afirmativas, revelaram não haver discrepâncias significativas entre estas modalidades, como pode ser observado na Figura 4.

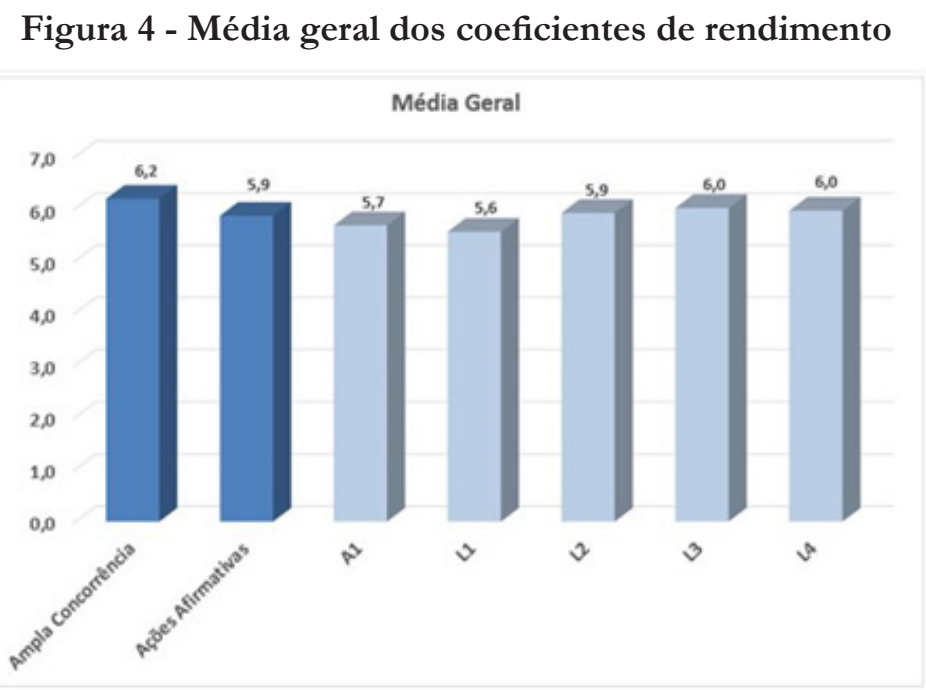

Fonte: dados da pesquisa

A segunda análise realizada separou a média por semestre, e a diferença se manteve não significativa. Destaca-se que nos semestres de 2014.2 e de 2015.1, houve um melhor desempenho acadêmico entre os alunos ingressantes por meio de ações afirmativas, como apresentado na Figura 5.

\section{Figura 5-Média dos coeficientes de rendimento por semestre}

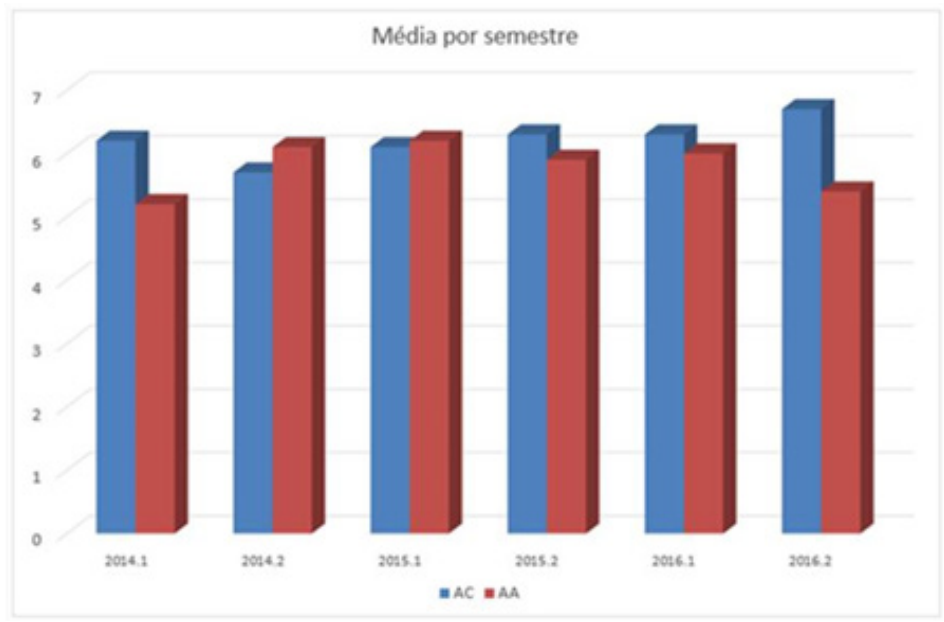

Fonte: dados da pesquisa 
Tanto a análise da média geral quanto da média por semestre, demonstram não haver discrepância significativa no desempenho acadêmico entre os cotistas e os não cotistas. Esses resultados reafirmam os estudos de autores como Alvarenga et al., (2012), Matos et al., (2012) e Queiroz et al., (2015), de que a implementação de políticas públicas de ações afirmativas não interfere na qualidade do ensino e no desempenho acadêmico dos discentes.

Foi realizada também uma análise do desempenho acadêmico entre os cotistas e não cotistas por outra perspectiva, isto é, de modo individual. Os CR's foram classificados por ordem decrescente e foram selecionados os melhores e os piores coeficientes de rendimento dentro de uma amplitude de $10 \%$, ou seja, os 27 melhores e piores CR's.

\section{Figura 6 - Melhores CR's (10\% melhores)}

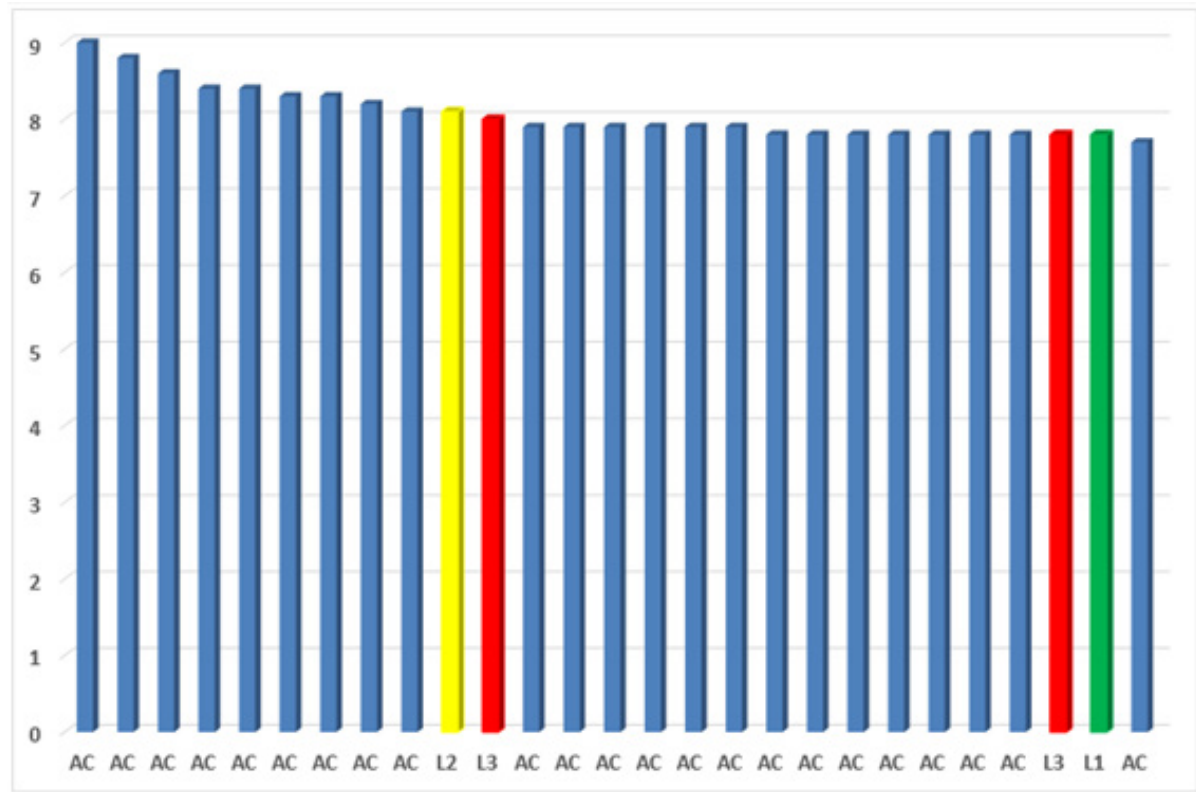

Fonte: dados da pesquisa

Como pode ser observado na figura 6 , a maior parte da amostra dos melhores coeficientes de rendimento é composta por alunos que ingressaram por meio da modalidade de ampla concorrência. Os alunos ingressantes por meio de Ações Afirmativas (AA) representaram 18,5\%, um resultado bem inferior aos alunos ingressantes por meio de Ampla Concorrência (AC). Entretanto, cabe ressaltar que ao comparar as distâncias percentuais entre todos estudantes, as diferenças entre eles tornam-se irrelevantes, do ponto de vista estatístico. 
Ao analisar o outro extremo, isto é, a amostra com os piores coeficientes de rendimento, o resultado torna-se equilibrado, conforme apresentado na Figura 7.

\section{Figura 7 - piores CR's (amostra de 10\%)}

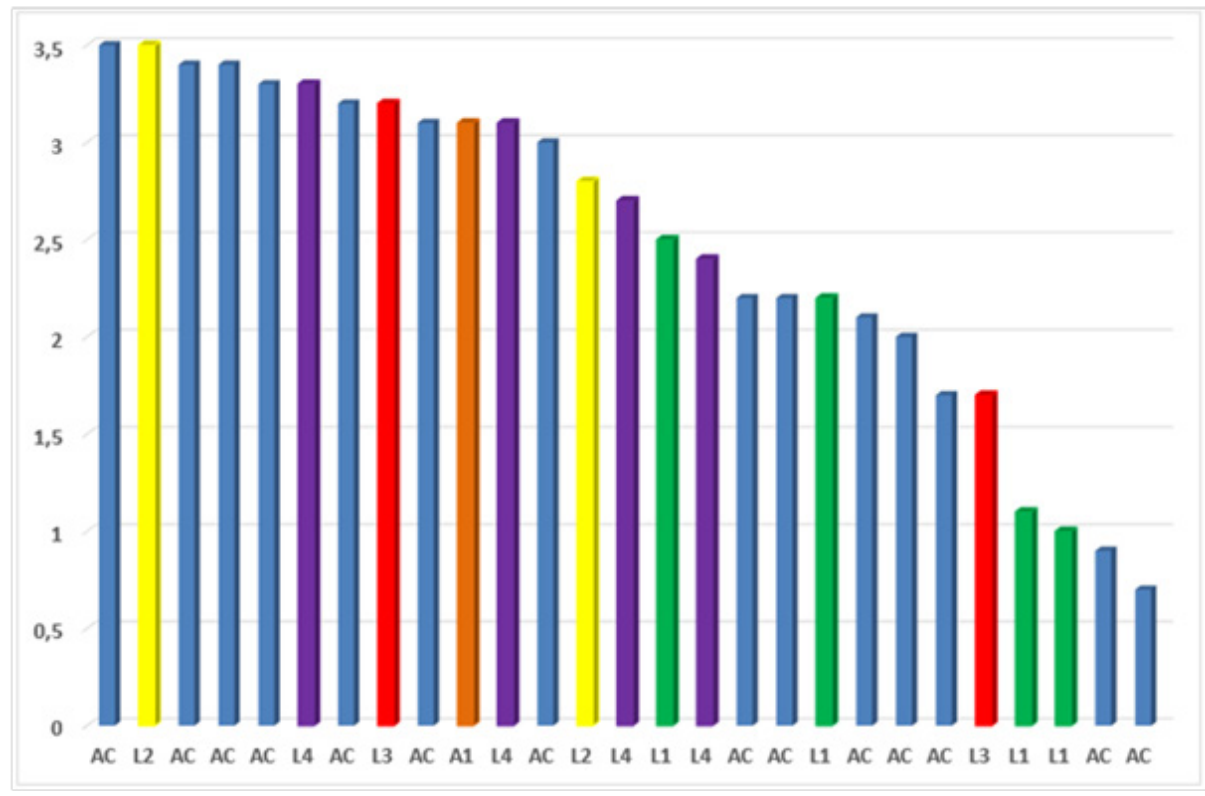

Fonte: dados da pesquisa

Quando analisados os piores CR's observa-se que alunos cotistas representam $48 \%$, o que sinaliza um equilibrio entre as duas categorias.

Por fim, os CR's dos grupos foram divididos em quartil e verificadas as médias dos CR's dos cotistas e não cotistas em cada quartil, conforme apresentado na Figura 8. Estes dados reforçam os resultados apresentados previamente, com o desempenho dos alunos de ações afirmativas posicionados um pouco abaixo do desempenho dos alunos de ampla concorrência. Assim, a princípio, pode se afirmar que a política de ação afirmativa de cotas não impactou negativamente na formação do egresso do curso avaliado. 
Figura 8 - Médias dos CR's por quartil

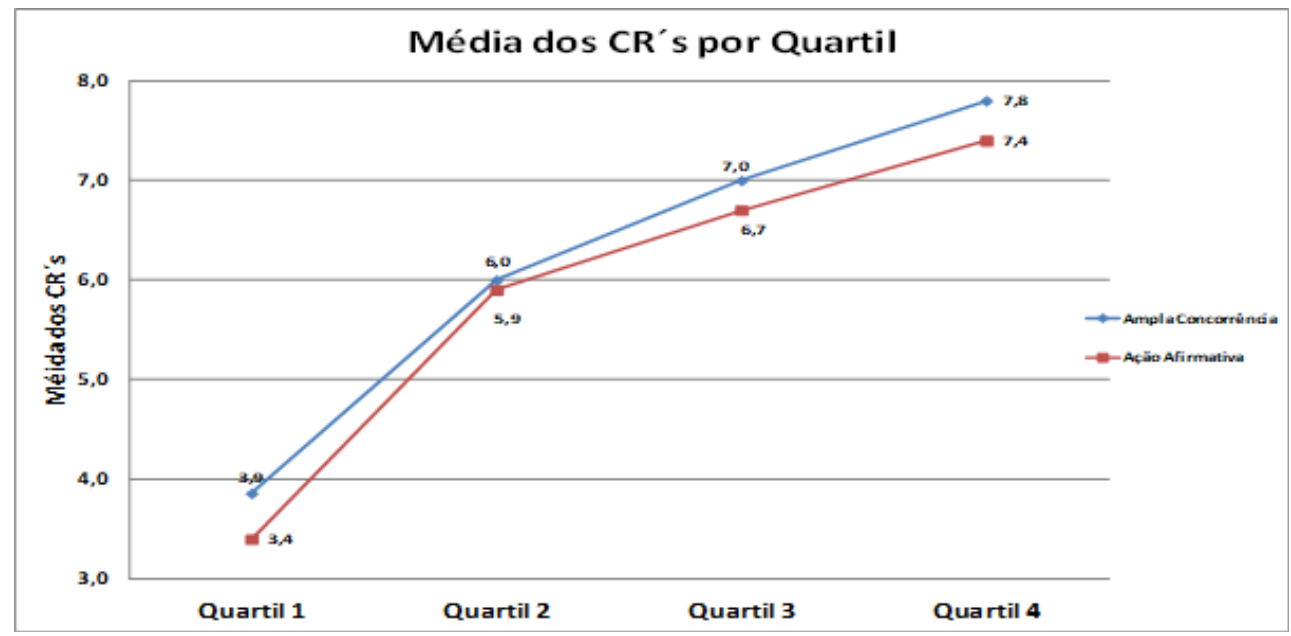

Fonte: dados da pesquisa

\section{CONSIDERAÇÕES FINAIS}

A presente pesquisa teve por objetivo analisar o desempenho dos alunos ingressantes por meio das cotas provenientes das políticas de ações afirmativas comparando-o ao desempenho dos alunos ingressantes por ampla concorrência do curso de Administração do Instituto de Ciências Humanas e Sociais da Universidade Federal Fluminense.

A partir dos dados do Coeficiente de Rendimento Acadêmico (CR) dos discentes que ingressaram nos semestres letivos que antecederam a efetiva implementação da Lei no 12.711/12 (1.2014 - 2.2014 - 1.2015 e 2.2015) e os ingressantes dos semestres que sucederam a integral implantação da referida Lei, foram realizadas análises estatísticas descritivas.

Os resultados evidenciam que apesar de existir uma diferença entre os CR's, as modalidades criadas para atender a Lei no 12.711/12 (L1, L2, L3 e L4) comparadas à modalidade de ampla concorrência, não são suficientemente discrepantes para se afirmar que a adoção de cotas prejudicou o resultado da formação dos alunos egressos. Dessa forma, é possível afirmar, para a amostra selecionada, que discursos discriminatórios e elitistas, que sugerem um suposto "nivelamento por baixo" são completamente infundados. Ao contrário, distanciam as possibilidades de aproximação das condições de igualdade e favorecem as metanarrativas equivocadas sobre a validade da "meritocracia". 
Visando aprofundar a pesquisa, optou-se por também realizar a análise do desempenho por semestre letivo e os resultados ratificaram o fato de que não há diferenças consideráveis nos CR's obtidos pelos alunos cotistas comparados aos dos não cotistas. Além disso, pôde-se observar que nos semestres de 2014.2 e de 2015.1 os alunos que ingressaram por meio de ações afirmativas obtiveram um desempenho acadêmico superior ao dos ingressantes por ampla concorrência.

Com os resultados da pesquisa, observa-se que além de ser um mecanismo eficaz, a política pública de ações afirmativas possui vasta importância para a sociedade, especialmente para aqueles que não possuíam oportunidades de acesso às universidades públicas por sofrerem discriminação social e racial.

Sugere-se para pesquisas futuras, uma maior abrangência das amostras, contemplando outros cursos de graduação, objetivando analisar se os resultados obtidos com o curso de administração se mantêm para os demais cursos do Instituto de Ciências Humanas e Sociais da Universidade Federal Fluminense.

\section{REFERÊNCIAS}

ALVARENGA, C. F. et al. Desafios do ensino superior para estudantes de escola pública: um estudo na UFLA. Revista Pensamento Contemporâneo em Administração, v. 6, n. 1, p. 55-71, 2012.

BEZERRA, T. O. C.; GURGEL, C. R. M. A política pública de cotas em universidades, enquanto instrumento de inclusão social. Pensamento \& Realidade, v. 27, n. 2, p. 95-117, 2012.

BRASIL. Lei $\mathbf{n}^{\mathbf{0}}$ 12.711, de 29 de agosto de 2012. Dispõe sobre o ingresso nas universidades federais e nas instituições federais de ensino técnico de nível médio e dá outras providências. Diário Oficial da União, Brasília, DF, 30 ago. 2012. Seção 1, p. 1-2.

CAMPOS, L. C. et al. Cotas sociais, ações afirmativas e evasão na área de Negócios: análise empírica em uma universidade federal brasileira. Revista Contabilidade \& Finanças, v. 28, n. 73, p. 27-42, 2017.

CARVALHO, M. M. A educação superior no Brasil: o retorno privado e as restrições ao ingresso. Sinais Sociais, Rio de Janeiro, v. 5, n. 15, p. 82-109, 2011.

DURHAM, E. R. Inequality in education and quotas for black students in universities. Novos Estudos-CEBRAP, v. 1, n. SE, p. 0-0, 2005. 
FERES JR, J.; DAFLON, V. T. Ação afirmativa na Índia e no Brasil: um estudo sobre a retórica acadêmica. Sociologias, v. 17, n. 40, p. 92-123, 2015.

FERES JR, J.; DAFLON, V. T.; CAMPOS, L. A. Ação afirmativa, raça e racismo: uma análise das ações de inclusão racial nos mandatos de Lula e Dilma. Revista de Ciências Humanas, Viçosa, v. 12, n. 2, p. 399-414, 2012.

GIL, A. C. Como elaborar projetos de pesquisa. São Paulo: Atlas, 2002.

IIZUKA, E. S. A Política de Cotas nas Universidades Brasileiras: como ela chegou à agenda de Políticas Públicas? [The Quotas Policy in Brazilian Universities: how it got agenda Public Policy?]. Amazônia, Organizações e Sustentabilidade, v. 5, n. 2, p. 51-48, 2016.

LIMA, M. Desigualdades raciais e políticas públicas: ações afirmativas no governo Lula. Novos estudos CEBRAP, n. 87, p. 77-95, 2010.

MARCONI, M. A.; LAKATOS, E. M. Metodologia de pesquisa. São Paulo: Atlas, 2004.

MATOS, M. S. et al. O impacto do Programa de Inclusão Social da Universidade de São Paulo no acesso de estudantes de escola pública ao ensino superior público gratuito. Revista Brasileira de Estudos Pedagógicos, v. 93, n. 235, p. 720-742, 2012.

MOEHLECKE, S. Ação afirmativa: história e debates no Brasil. Cadernos de pesquisa, n. 117, p. 197-217, 2002.

MORESI, E. Metodologia da pesquisa. Brasília: Universidade Católica de Brasília, 2003.

OLIVEIRA, J. F. et al. Democratização do acesso e inclusão na educação superior no Brasil. Educação Superior no Brasil 10 anos pós-LDB, p. 71 citation_ lastpage $=88,2008$.

OLIVEN, A. C. Ações afirmativas, relações raciais e política de cotas nas universidades: Uma comparação entre os Estados Unidos e o Brasil. Educação, v. 30, n. 61, p. 29-51, 2007. 
PIOVESAN, F. Ações afirmativas da perspectiva dos direitos humanos. Cadernos de pesquisa, v. 35, n. 124, p. 43-55, 2005.

QUEIROZ, Z. C. L. S. et al. A lei de cotas na perspectiva do desempenho acadêmico na Universidade Federal de Uberlândia. Revista Brasileira de Estudos Pedagógicos, v. 96, n. 243, p. 299-320, 2015.

RICHARDSON, R. J.; PERES, J. A. Pesquisa social: métodos e técnicas', Atlas. São Paulo, 1999.

SANTOS, A. P. Itinerário das ações afirmativas no ensino superior público brasileiro: dos ecos de Durban à Lei das Cotas. Revista de Ciências Humanas, n. 2, p. 289-317, 2012.

SOUZA, C. Políticas públicas: uma revisão da literatura. Sociologias, n. 16, p. 20-45, 2006.

UFF. Resolução N. ${ }^{\circ}$ 001/2015. Ministério da Educação e Cultura - MEC. Universidade Federal Fluminense - UFF. Disponível em: < http://www.proac.uff. br/econ/sites/default/files/001-2015_regulamento_do_curso_de_graduacao_0. pdf $>$. Acesso em: 05 de jan. 2018

VELLOSO, J. Cotistas e não-cotistas: rendimento de alunos da Universidade de Brasília. Cadernos de pesquisa, v. 39, n. 137, p. 621-644, 2009.

WALTENBERG, F. D.; CARVALHO, M. D. Cotas aumentam a diversidade dos estudantes sem comprometer o desempenho. Sinais Sociais, v. 20, n. 7, p. 36-77, 2013.

\footnotetext{
André Ferreira

Doutorado em Políticas Públicas pelo IE/ PPED - UFRJ, Brasil. Professor Adjunto IV - Programa de Pós-Graduação em Administração (PPGA/UFF). E-mail: andref@id.uff.br

Raquel de Souza Corrêa

Graduada em Administração - UFF (Universidade Federal Fluminense), Brasil. E-mail: raquelcorrea.adm@gmail.com
} 


\section{Thamires Domingos Paredes Galantini}

Mestrado Profissional em Administração Pública (em andamento). E-mail: thamiresparedes@id.uff.br

\section{Márcio Moutinho Abdalla}

Doutorado em Administração - FGV-EBAPE, Brasil. Professor Adjunto III - Programa de Pós-Graduação em Administração (PPGA/UFF) E-mail: marcioabdalla@id.uff.br

Recebido em 03/04/2020

Aprovado em 30/09/2020 